\title{
Molecular variations in Lenzites species collected from Nigeria and other parts of the world using Internal Transcribed Spacers (ITS) regions of Ribosomal RNA
}

\author{
Oyetayo $\mathrm{OV}^{\mathbf{1}^{*}}$ \\ ${ }^{1}$ Department of Microbiology, Federal University of Technology, P.M.B. 704, Akure, Nigeria.
}

Oyetayo OV 2018 - Molecular variations in Lenzites species collected from Nigeria and other parts of the world using Internal Transcribed Spacers (ITS) regions of Ribosomal RNA. Microbial Biosystems 3(2), 40-45.

\begin{abstract}
The phylogeny of six specimens of Lenzites species collected from Akure Nigeria was studied using molecular data obtained by sequencing the internal transcribed spacers (ITS) regions of ribosomal RNA using universal primers (ITS4 and ITS5). Preliminary basic local alignment search tool (BLAST) revealed the identity of the specimens from Akure as Lenzites species. The percentage relationship between rRNA gene sequences of Lenzites species from Akure and Lenzites species sequences in NCBI GenBank database showed 99 to 100 similarity. Phylogenetic tree generated using MEGA 4 software strongly supported Lenzites clade that includes most Lenzites species together with species of Trametes and Daedalea which are considered as synonyms of Lenzites species. The rRNA gene sequences of three of the Lenzites species designated specimens 1, 3 and 6 were in the same clade with most of the Lenzites species collected from NCBI GenBank. Generally, specimens 1 to 6 form a monophyletic group with Lenzites species collected from other parts of the world. The results revealed the relationship of Lenzites species collected from Nigeria with Lenzites species with other parts of the world.
\end{abstract}

Key words - Polyporoid, Lenzites species, Phylogeny, rDNA, ITS.

\section{Introduction}

Macrofungi are known to be rich sources of bioactive compounds with great therapeutic properties (Liu 2007). Several bioactive compounds with positive physiological properties had been found in macrofungi. Some of these bioactive compounds are glycolipids, compounds derived from shikimic acid, aromatic phenols, fatty acid derivatives, polyacetylamine, polyketides, nucleosides, sesterterpenes, polysaccharides and many other substances of different origins (Lorenzen and Anke 1998; Wasser and Weis 1999; Mizuno 1999 and Liu 2007). They are known to be medically active in several therapies, such as antioxidant, antitumor, antibacterial, antiviral, hematological and immunomodulation (Wasser and Weis 1999; Lindequist et al. 2005).

It has been reported that 140,000 macrofungi are on earth and out of these only 14,000 (10\%) are known (Lindequist et al. 2005). Presently, most macrofungi in Africa are yet to be correctly identified. Specifically, the pore fungi of tropical areas remain under studied (DouanlaMeli et al. 2007). This is as a result of lack of well trained manpower and state of the earth 
equipment. Previous identification is based on morphological description of the fruiting bodies, host specificity, and geographical distribution (Seo and Kirk 2000). Morphologically, mushrooms belonging to the same and even different genera may look similar. Hence, morphological characteristics have their limitations in allowing a reliable distinction of intraspecific characteristics.

Lenzites spp are characterized by the combination of pileate basidiocarps, poroid hymenophore, trimitic hyphal system, thin-walled smooth basidospores not reacting in presence of Melzer's reagent and production of a white-rot type of wood decay (Gilbertson and Ryvarden 1987). Two common synonyms of the genera Lenzites are Daedalea and Trametes. Members of the polyporoids are similar mophologically. However, recent molecular studies have helped to clarify the higher level of and generic relationship of polyporoid (Justo and Hibbett 2011). Ribosomal RNA (rRNA) gene sequences have provided a wealth of information concerning phylogenetic relationships (Hillis and Dixon 1991), and studies of rRNA gene sequences have been used to infer phylogenetic history across a very broad spectrum, from studies among the basal lineages of life to relationships among closely related species and populations (Yang 2011). The objectives of the present study are to ascertaining the phylogenetic relationship between Lenzites species collected in Akure Nigeria by sequencing of the ITS region of the rRNA gene and comparing the gene sequences of these Lenzites species with sequences obtained from the NCBI Genbank.

\section{Materials and Methods \\ Fungal material}

Fresh fruiting bodies of Lenzites species were collected from Akure, Nigeria. The fruitbodies were kept dry in tissue papers that were placed in a polythene paper containing silica gel. The polythene bags containing the samples were well labeled for easy identification and taken to the laboratory for further examination. Herbarium samples of Lenzites fruitbodies were kept at the herbarium of Institute of Microbiology, Chinese Academy of Sciences, Beijing.

\section{Extraction of DNA}

Standard DNA isolation methods employing cetyltrimethylammonium bromide (CTAB) lysis buffer (Zolan and Pukkila 1986) was used. Briefly, dried portions of Lenzites fruitbodies (2g) were ground with a mortar and pestle. The grounded materials were transferred into well labeled microtubes. Prewarmed $\left(60^{\circ} \mathrm{C}\right)$ extraction buffer $(\mathrm{CTAB})$ was added and the tubes were incubated at $65^{\circ} \mathrm{C}$ for 30 to 60 minutes. Equal volume of chloroform and alcohol (24:1) was added and mixed by inverting tubes for 15 minutes. The tubes were centrifuge for 10 minutes at $10,000 \mathrm{~g}$ (13000rpm). The process was repeated but the time of mixing was 3 minutes and time of centrifugation was 5 minutes at the same speed as above. Upper aqueous layers were removed into clean tubes and $40 \mu \mathrm{l} \mathrm{NaAc}$ was added followed by $260 \mu \mathrm{l}$ of cold isopropanol. This was gently mixed by inverting tubes. The tubes were incubated at $-20^{0} \mathrm{C}$ overnight. On the second day, the mixture was centrifuged at 10,000g (13000rpm) for 10 minutes. The supernatant was discarded and pellets rinsed with $70 \%$ alcohol and mixed for sometimes. This procedure was repeated three times. After discarding the supernatant, the sample was dried in a dryer for 20 minutes at room temperature. Pellets were resuspended in $30 \mu \mathrm{TE}$. DNA concentration and quality was checked by observing the band on an ethidium-stained agarose gel $(0.7 \%)$ using $0.2 \mu l$ of each sample.

\section{PCR amplification of the ITS region}

The entire region of ITS4 and ITS5 were amplified by PCR using the universal primers (Gardes and Bruns 1993). The reaction mix was made up to a total volume of $25 \mu \mathrm{l}$, composed of $23 \mu \mathrm{l}$ of Taq polymerase "Ready to Go" mixture (Pharmacia, mention place first time) with 0.2 $\mu \mathrm{l}$ of each primer $(100 \mathrm{pM})$ and $2 \mu \mathrm{l}$ of DNA solution (here you need to give the concentrataion, 
even if only roughly). The tubes were placed in a thermal cycler (GenAmp PCR System 2400, Perkin-Elmer, place) for amplification under the following conditions: 30 cycles of (1) denaturation at $95^{\circ} \mathrm{C}$ for $30 \mathrm{~s}$, (2) annealing at $50^{\circ} \mathrm{C}$ for $1 \mathrm{~min}$, (3) extension at $72^{\circ} \mathrm{C}$ for $1 \mathrm{~min}$ were these steps repeated?. The amplification products were purified using a PCR Purification Kit (company?) and electrophoresed on ethidium-stained agarose gel $(0.7 \%)$ to check the purity. DNA sequencing was performed using the primers the same primer pair used in the PCR reactions (ITS 4 and ITS 5) in an Applied Biosystem DNA Analyser.

\section{Alignment of sequence}

Alignments (pairwise and multiple alignment) were performed with the Clustal W package (Thompson et al. 1997). The aligned sequences were corrected manually, focusing on gap positions. DNA sequence data were analyzed to provide pairwise percentage sequence divergence. The data obtained from the sequence alignment were used to plot a tree diagram (MEGA 4 Software).

\section{Results}

The ITS primer produced single PCR product for the Lenzites species designated specimens 1 to 6 with sequence lenght that ranged from 600 to 620bp (Table 1). The percentage level of relationship of the six Lenzites species collected from Nigeria to existing Lenzites species ranged from 99 to 100\% (Table 2). The results of the ITS gene sequence obtained from NCBI GenBank BLAST discriminated between all the Lenzites species. Lenzites species designated specimen 1 collected from Nigeria was 100\% to homologus Lenzites species with ascension number JX082361.1 collected from French Guiana (Table 2). The phylogenetic tree generated placed specimens 1, 3 and 6 in the same clade with Lenzites species and Daedaleopsis flavida (Fig. 1).

Table 1 Length of ITS region of Lenzites species collected in Akure, Nigeria.

\begin{tabular}{lll}
\hline Code & Tentative Identity & Length of ITS Region (bp) \\
\hline Specimen1 & Lenzites species & 610 \\
Specimen2 & Lenzites species & 620 \\
Specimen3 & Lenzites species & 600 \\
Specimen4 & Lenzites species & 600 \\
Specimen5 & Lenzites species & 600 \\
Specimen6 & Lenzites species & 610 \\
\hline
\end{tabular}

Bp: Base pair

Table 2 Genomic identification obtained from NCBI BLAST search based on the ITS rDNA sequences of Lenzits species collected in Akure, Nigeria.

\begin{tabular}{|c|c|c|c|c|c|}
\hline Code & $\begin{array}{l}\text { Tentative } \\
\text { Identity }\end{array}$ & $\begin{array}{l}\text { Culture of } \\
\text { Closest relative }\end{array}$ & $\begin{array}{l}\text { Ascenssion } \\
\text { number of } \\
\text { relative }\end{array}$ & Origin & $\begin{array}{l}\text { \% Level of } \\
\text { relationship }\end{array}$ \\
\hline Specimen1 & Lenzites species & BRFM 1079 & JX082361.1 & French Guiana & 100 \\
\hline Specimen 2 & Lenzites species & BRFM 1079 & JX082361.1 & French Guiana & 99 \\
\hline Specimen3 & Lenzites species & BRFM 1079 & GU731566.1 & Marseille & 99 \\
\hline Specimen4 & Lenzites species & BRFM 1079 & JX082361.1 & French Guiana & 99 \\
\hline Specimen5 & Lenzites species & BRFM 1079 & JX082361.1 & French Guiana & 99 \\
\hline Specimen6 & Lenzites species & BRFM 1079 & JX082361.1 & French Guiana & 99 \\
\hline
\end{tabular}




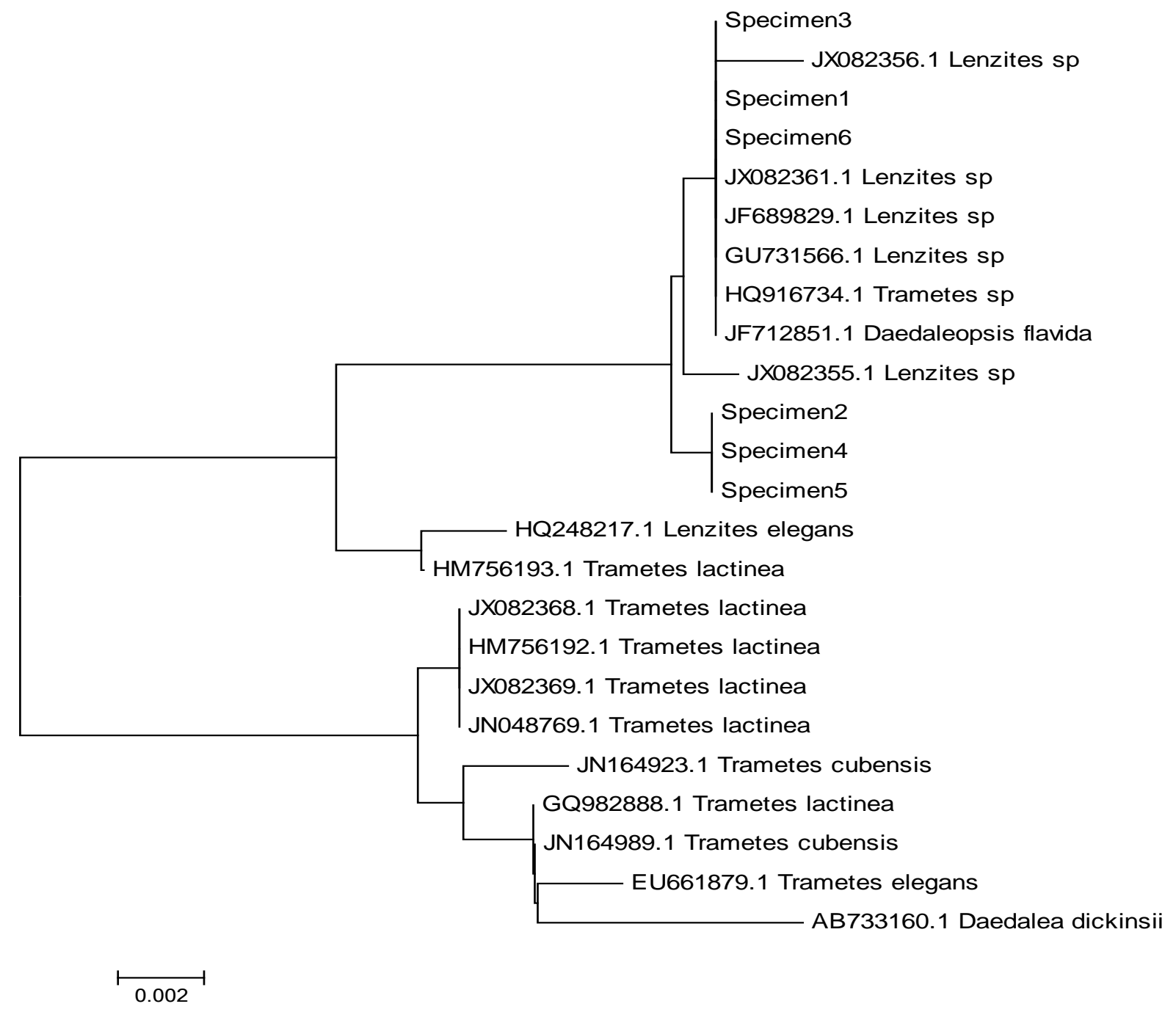

Fig. 1 - Phylogenetic tree of the Genus Lenzites collected from Nigeria based on nucleotide sequences of the ITS region.

\section{Discussion}

Correct identification of macrofungi had been a challenge in most developing Countries. This is as a result of the use of morphological description mostly employed by mycologist in this part of the world. It has been observed that morphological description have limitation in not allowing a reliable distinction of intraspecific characteristics (Seo and Kirk 2000). Molecular techniques could be used to adequately characterize and identify intra and inter specific characteristics (Zakaria et al. 2009). Hence, a molecular technique was employed in this study to resolve conflicting data from morphological characteristics in the identification of Lenzites species collected from Nigeria.

The sequence lenght obtained ranged from 600 to 620bp (Table 1). Min and Hickey (2007) had earlier reported that the standard short barcode sequences ( $\sim 600 \mathrm{bp}$ ) are sufficient for species identification among the fungi. It has also been reported that Ribosomal DNA (rDNA) sequences provides a wealth of information concerning phylogenetic relationships (Hillis and Dixon 1991), and studies of rDNA sequences have been used to infer phylogenetic history across 
a very broad spectrum, from studies among the basal lineages of life to relationships among closely related species and populations (Yang 2011). In the present study, sequences obtained from rDNA of the six macrofungi specimens collected in Nigeria tentatively confirm the identity as Lenzites species collected from Nigeria and the relationship with existing Lenzites species from other parts of the world (Table 2). It is a well known fact that members of the polyporoids are similar mophologically. However, molecular studies can help to clarify the higher level of and generic relationship of polyporoid (Justo and Hibbett 2011).

Daedaleopsis has been described as synonym of Lenzites (Kirk et al. 2008). In a study, Justo and Hibbett (2011) proposed that the genera Artolenzites, Coriolopsis, Coriolus, Cubamyces, Cyclomycetella, Lenzites, Poronidulus, Pseudotrametes and Pycnoporus are considered synonyms of Trametes. The phylogenetic tree (Fig. 1) generated also revealed that Lenzites specimens 1 to 6 form a monophyletic group with existing Lenzites species obtained from NCBI GenBank. The monophyletic nature of specimens 1 to 6 and Lenzites species from the GenBank indicates that they are from the same ancestral stock. Lenzites species designated specimens 2,4 and 5 form a separate clade within the monophyletic tree housing the Lenzites species. These three Lenzites species (specimens 2,4 and 5) may be new species of Lenzites. Earlier information on Lenzites species shows that it is a genus of fungi in the family Polyporaceae. It was circumscribed by Elias Magnus Fries in 1835. Lenzites species is widespread and it is made up of six species (Kirk et al., 2008).

Conclusively, phylogenetic analysis of the ITS región of the rDNA of specimens 1 to 6 clearly resolved the identity of macrofungi designated specimens 1 to 6 collected from Nigeria as Lenzites species. Moreover, the percentage relationship of these Lenzites species (specimens 1 to 6) and their relationship with Lenzites species from other parts of the world was also revealed.

\section{Aknowledgement}

The authors wish to acknowledge the financial support of Chinese Academy of Sciences (CAS). Oyetayo, V.O. is a CAS President's International Fellowship Initiative (PIFI) awardee at Institute of Microbiology, Chinese Academy of Sciences, Beijing, China. Prof. Y.-J, Yao is also acknowledged for hosting Oyetayo, V.O in his laboratory (Key Laboratory of Systematic Mycology and Lichenology, Institute of Microbiology, Chinese Academy of Sciences, Beijing 100101, Peoples’ Replublic of China).

\section{References}

Douanla-Meli C., Ryvarden L. and Langer E. 2007. Studies of tropical African pore fungi (Basidiomycota, Aphyllophorales): three new species from Cameroon. Nova Hedwigia, 84: 409-420.

Gardes M. and Bruns T. D. 1993. ITS primers with enhanced specificity for basidiomycetes application to the identification of mycorrhizae and rusts. Molecular Ecology, 2(2): 113118.

Gilbertson R. L. and Ryvarden L. 1987. North American polypores, vol. 2. Synopsis Fungorum Special Volume. Oslo: Fungiflora.

Hills D. M. and Dixon M. T. 1991. Ribosomal DNA: molecular evolution and phylogenetic inference. Q Rev Biol, 66:411-453.

Justo A. and Hibbett D. S. 2011. Phylogenetic classification of Trametes (Basidiomycota, Polyporales) based on a five-marker dataset. Taxon, 60(6): 1567-1583.

Kirk P. M., Cannon P. F., Minter D. W. and Stalpers J. A. ed. 2008. Ainsworth and Bisby's Dictionary of the Fungi. 10th Edition ed. CABI Publishing.

Lindequist U., Niedermeyer T. H. J. and Julich W-D. 2005. The pharmacological potential of mushrooms-Review. E CAM, 2(3): 285 - 299. 
Lorenzen K. and Anke T. 1998. Basidiomycetes as a source for new bioactive natural products. Current Organic Chemistry, 2:329-64.

Liu J-K. 2007. Secondary metabolites from higher fungi in China and their biological activity. Drug Discov. Ther., 1(2): $94-103$.

Min X. J. and Hickey D. A. 2007. Assessing the effect of varying sequence length on DNA barcoding of fungi. Mol. Ecol. Notes., 7(3): 365-373.

Mizuno T. 1999. The extraction and development of antitumor active polysaccharides from medicinal mushrooms in Japan- review. Int J Med Mushr., 1: 9-30.

Seo G. S. and Kirk P. M. 2000. Ganodermataceae: Nomenclature and classification, In: Flood, J., P.D. Bridge and P. Holderness (Eds.),Ganoderma Disease of Perennial Crops. CABI Publishing, Walling Ford, UK., pp. 3 - 22.

Thomson J. D., Gibson T. J., Plewniak F., Jeanmougin F. and Higgins D. G. 1997. The Clustal_X windows interface: Flexible strategies for multiple sequence alignment aided by quality analysis tools. Nucleic Acids Res., 25: 4876-4882.

Wasser S. P. and Weis A. L. 1999. Therapeutic effects of substances occurring in higher basidiomycetes mushrooms a modern perspective. Critical review of immunology, 19 (1): 65-96.

Yang Z. L. 2011. Molecular techniques revolutionize knowledge of basidiomycetes evolution. Fungal Diversity, 50:47-58. 